\title{
Clinical Supportive and Palliative Care
}

\section{P 100 NUTRITIONAL ASSESSMENT AND MANAGEMENT - AN AUDIT OF CURRENT PRACTICE}

Emma Longford, ${ }^{1}$ Paula Powell, ${ }^{2}$ Clare Horlick, ${ }^{3}$ Margaret Kendall, ${ }^{5}$ Elen Royles, ${ }^{5}$ Elaine Hamill, ${ }^{6}$ Catherine Cliff, ${ }^{7}$ Alison Young ${ }^{4} .{ }^{1}$ Wirral Hospice St Johns, Wirral, United Kingdom; ${ }^{2}$ Willowbrook Hospice, Prescot, Merseyside; ${ }^{3}$ Woodlands Hospice, Aintree, Merseyside; ${ }^{4}$ Royal Liverpool University Hospital, Merseyside; ${ }^{5}$ Warrington \& Halton Hospitals NHS Foundation Trust, Cheshire; ${ }^{6}$ Marie Curie Hospice, Liverpool, Merseyside; ${ }^{7}$ Wirral Community NHS Trust

\subsection{6/bmjspcare-2014-000654.141}

Background Undernutrition affects up to $97 \%$ of patients with cancer and is strongly associated with poor outcome. Eating is an important quality-of-life issue with many social activities centring on dining. Assessment of patients' nutritional status and appropriate support is fundamental to palliative care at all stages. An audit was undertaken of current practice with regards to nutritional assessment and management within Merseyside \& Cheshire Cancer Network (MCCN), the results of which are presented.

Method The audit consisted of three parts a) telephone survey of nutrition resources within specialist palliative care services (SPCS), b) web-based survey determining healthcare professionals (HCPs) perceptions of practice c) supplementary web-based survey focusing on key issues.

Results The majority of SPCS inpatient units do not have a nutrition policy or lead. None of the SPCS units had access to educational information regarding nutrition in palliative care.

110 HCPs completed the initial survey, 60 HCP's completed the follow-up survey. $90 \%$ routinely discuss nutrition with their patients. The majority (64\%) do not use any form of nutritional screening assessment; however within most MDT's (69\%) there is access to specialist nutritional advice. Within all hospital settings there is a well adhered to protected mealtime policy, however only $58 \%$ of those working in SPCS inpatient units are aware of a protected mealtime policy. $64 \%$ of respondents advise prescription of oral nutritional supplements regularly. All respondents suggest prescription of dexamethasone for appetite stimulation 'sometimes' or 'often', whilst only 59\% suggest prescription of megestrol 'sometimes'. $44 \%$ of respondents had received no nutritional training.

Conclusions There is paucity of nutritional guidance within SPCS, although in most cases there is access to appropriate specialist advice. Training needs to be improved to increase confidence in management of nutritional issues. MCCN guidelines for assessment and provision nutritional care have subsequently been published. 